\title{
El asentamiento Pircas: Nuevas evidencias de tempranas ocupaciones agrarias en el norte de Chile
}

LAUTARo NÚÑ̃EZ ${ }^{1}$

\section{Introducción}

Se encuentra en curso una valoración multidisciplinaria de las tempranas ocupaciones agrarias en el curso inferior de la quebrada de Tarapacá. Recientes prospecciones y pruebas estratigráficas (Núñez 1982) en la banda norte del distrito Caserones nos permitieron identificar un asentamiento agrario inédito que hemos denominado Pircas. El presente artículo da cuenta preliminarmente de sus principales indicadores morfológicos, antropológicos, culturales y cronológicos e inserta su problemática en el contexto del distrito Caserones. ${ }^{2}$

\section{El marco de referencia}

La identificación de este singular asentamiento se debe a una sucesión de reconocimientos parciales en el borde septentrional de la quebrada de Tarapacá al frente del poblado temprano de Caserones. La primera prospección del distrito (Núñez 1965) no cubrió este sector por la dificultad de su acceso arenoso. Durante el segundo estudio de campo (Núñez 1972) se conocieron algunas "pircas" o estructuras de piedra poco diagnósticas apegadas al borde de la quebrada, pero la ausencia de rasgos culturales de superficie no permitió una afiliación cultural y cronológica adecuada. A través del Proyecto Tarapacá (True et al. 1970) otras estructuras fueron observadas pero tampoco se notaron evidencias elocuentes para definir su situación tempocultural. Sin embargo, parte del asentamiento fue reconocido como Tarapacá 1 a raíz principalmente del hallazgo de industrias líticas superficiales de burda percusión, sin puntas triangulares ni elementos de molienda. Frente a este registro decíamos: "las relaciones entre los artefactos y las estructuras no están claras. Esto

1 Instituto de Investigaciones Arqueológicas R. P. Gustavo Le Paige s. j., Universidad del Norte, San Pedro de Atacama, CHILE.

2 Este artículo es parte del proyecto: "Evaluación del potencial agropecuario inicial y puesta en valor de los primeros asentamientos en quebrada de Tarapacá (Caserones)", financiado por la Dirección de Investigaciones, Extensión y Asistencia Técnica de la Universidad del Norte. es sugerente, pero no está demostrado si las estructuras posdatan a los artefactos descritos" (True et al. 1970). Se revisaron estructuras cercanas al borde de la quebrada donde en efecto se registran zonas de talleres líticos y ausencia de cerámica, por lo que su filiación precerámica quedó planteada (True et al. 1970; Núñez 1972). En esa oportunidad se registraron artefactos líticos compuestos por raspadores pesados en lascas, rodados modificados, raspadores pesados planconvexos, núcleos, martillos, preformas, lascas gruesas usadas, bifaces crudas y lascas de uso cortante. $\mathrm{Al}$ ampliar el reconocimiento durante el Proyecto Caserones nos llamó la atención que gran parte de las estructuras no revisadas presentaban en superficie cerámica café alisada fragmentada, que, aunque en baja densidad, era suficientemente homogénea y unitariamente dispersa para ser tratada como rasgo "intrusivo". El test inicial realizado en uno de los recintos más representativos dio cuenta de evidencias agrocerámicas, por lo cual se inició una revaloración del borde norte del distrito Caserones, labor que se continuará por un amplio tiempo a raíz de la alta complejidad constructiva del espacio ocupado.

\section{Ubicación y características del asentamiento Pircas}

El total de ocupación cubre la planicie superior o nivel de Pampa que domina el borde norte de la quebrada de Tarapacá, desde la altura de las vertientes de Huarasiña (1500 m.snm) hasta la disolución de la alta planicie en Pampa del Tamarugal o Iluga (1175 m.snm), a lo largo de $7 \mathrm{~km}$ por un ancho variable de 200/400 m paralelo a la quebrada. Un típico patrón rural disperso demuestra una notable diseminación de estructuras vinculadas con el arroyo de Tarapacá, que corre por el fondo de la quebrada hacia Pampa del Tamarugal. Se trata de un ambiente hiperárido cuya naturaleza asociada a los recursos de oasis y bosque han sido comentados recientemente (Núñez 1982). Aunque se trata de un valle que no alcanza a drenar al mar, pertenece al medio ecológico desértico, propio de las tierras bajas de la Subárea Valles Occidentales (Figura 1). La mayor densidad de estructuras 


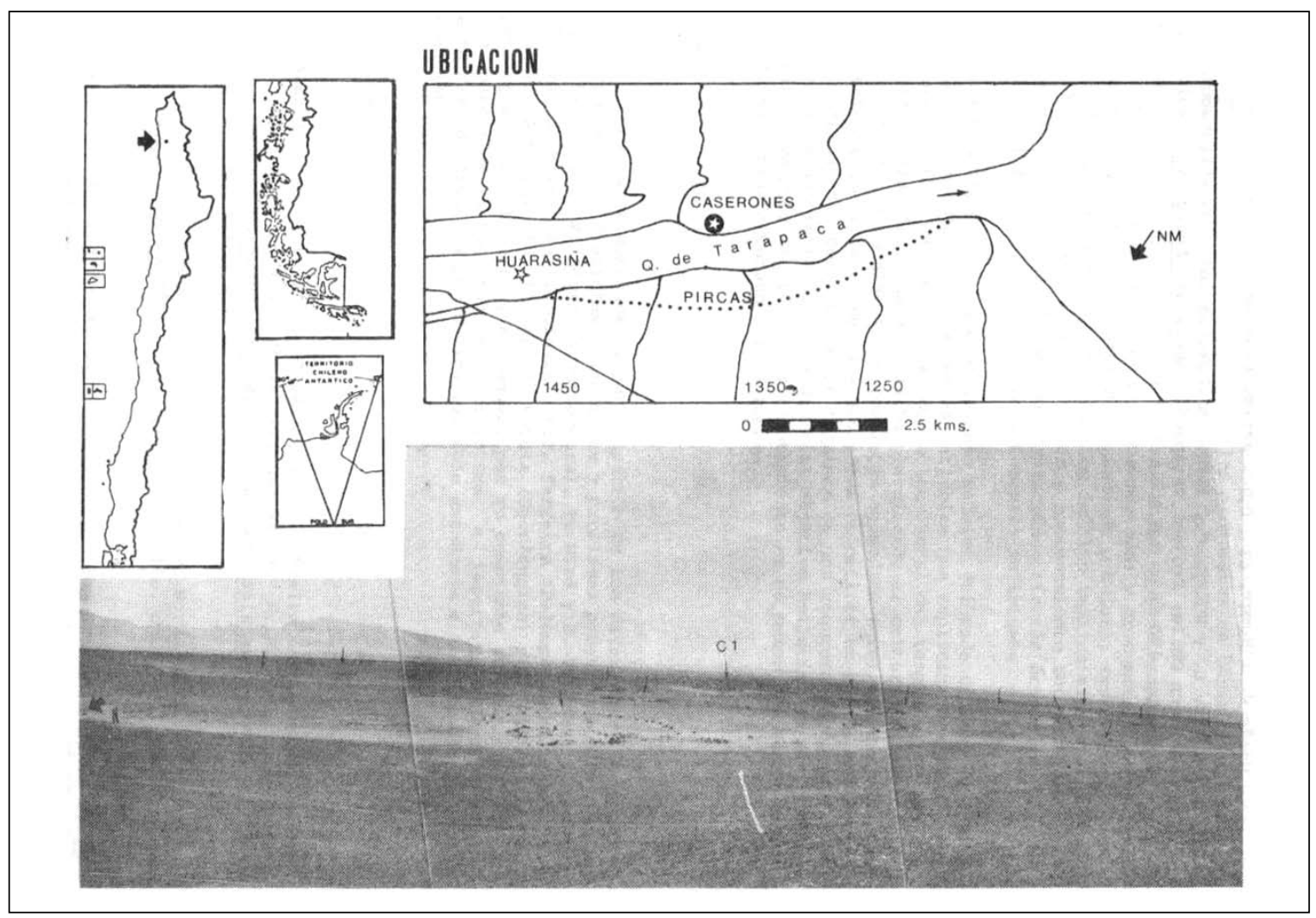

Figura 1. Ubicación del asentamiento Pircas en la quebrada de Tarapacá.

habitacionales se focaliza frente al poblado de Caserones y gradualmente disminuye hacia los extremos de Pampa del Tamarugal por el oeste y pueblo actual de Huarasiña hacia el este. A lo largo de esta planicie alta de ocupación los recintos se dispusieron tanto en el relieve planiforme como en leves hoyadas y débiles surcos de torrentes efímeros. El activo tráfico contemporáneo erosionó gradualmente las estructuras apegadas al borde de la quebrada y también a las emplazadas en los planos, conservándose mejor las situadas en las leves depresiones antes mencionadas.

Las evidencias comienzan a observarse a $1500 \mathrm{~m}$ aguas abajo del alto de Huarasiña a través de dos grandes círculos contiguos de más de $100 \mathrm{~m}$ de diámetro, con emplantillados de piedras en los núcleos. Cerca se detectan otros círculos más reducidos y varios emplantillados de piedras correspondientes a estructuras derrumbadas. En la medida que aumenta la distancia hacia el oeste de Huarasiña, disminuyen las estructuras, pero al acercarse a la zona eficiente de Caserones se intensifican los registros. En efecto, a $750 \mathrm{~m}$ aguas arriba de Caserones se inicia una mayor concentración a partir del cementerio Pircas 6, situado cerca de un geoglifo típico de Pircas correspondiente a un círculo con promontorio de piedras en el centro (Figura 2a). Las estructuras aumentan aguas abajo, nucleándose en los alrededores del cementerio Pircas 2, en donde hemos logrado un conteo más adecuado a la altura de Caserones. En efecto, al oeste de Pircas 2 la densidad es más elocuente, configurándose un eje de mayor relevancia a nivel de la zona de ocupación in toto.

Al considerar sólo estos dos focos (entre Pircas 6 y el sector nuclear frente a Caserones) se han registrado 56 conjuntos estructurados e individualizados con distintas funciones: doméstica, funeraria y ceremonial. Por esto, se debe esperar un total aproximado de 70 conjuntos, al sumar los registros de los extremos, en los bordes del este, oeste y norte, en donde hay recintos simples y periféricos dispuestos con mayores intervalos.

El catastro de estructuras y sitios interrelacionados de los dos focos referidos se resume en el Cuadro 1 : 


\begin{tabular}{|c|c|c|c|}
\hline $\begin{array}{l}\text { Conjunto } \\
\text { (Figura 2a) }\end{array}$ & Sigla & Clase & Descripción \\
\hline C. I & PIR-1 & $\begin{array}{l}\text { Conglomerado residencial (PR del } \\
\text { relevamiento). Ver panorámica en } \\
\text { Figura 5a y planta en Figura 3d. }\end{array}$ & $\begin{array}{l}\text { Conjunto de } 5 \text { a } 10 \text { recintos colmenados de plantas rectangulares con } \\
\text { ángulos curvados y muros de doble hilada. Extensas zonas de muros abatidos } \\
\text { configurando plantillados amorfos (sectores de patios). Delimitación de } \\
\text { recintos con muros periféricos contra dunas. Usos de pasadizos de circulación } \\
\text { interior. Actividades de taller y depósitos de maíz dentro de los recintos. } \\
\text { Restos de círculo concéntrico (alineamiento de piedras superficiales) en el } \\
\text { borde oeste (excavación de prueba). }\end{array}$ \\
\hline C. 2 & PIR-1 & $\begin{array}{l}\text { Conglomerado residencial y } \\
\text { atípicos. }\end{array}$ & $\begin{array}{l}\text { Dos conglomerados semialunados y separados con una planicie interior } \\
\text { protegida. Cada conglomerado no reconoce como un montículo leve delgado } \\
\text { y alargado }(70 \mathrm{~m}) \text { con evidencias superficiales de recintos restringidos, muros } \\
\text { de protección y adosamiento de estructuras. Hay leves depósitos de desecho } \\
\text { vegetal. Presencia de monolitos simples, talla lítica doméstica y de piedras } \\
\text { verdes de estatus (posible espacio ceremonial orientado paralelamente al } \\
\text { borde de la quebrada). }\end{array}$ \\
\hline C. 3 & PIR-1 & $\begin{array}{l}\text { Conglomerado residencial y ceremo- } \\
\text { nial (Figuras } 5 \text { b y } 6 c) \text {. }\end{array}$ & $\begin{array}{l}\text { Tres recintos contiguos asociados a semicírculo delimitado con bloques } \\
\text { superficiales alternados con un monolito central (espacio ceremonial). }\end{array}$ \\
\hline C. 4 & PIR-1 & $\begin{array}{l}\text { Estructura simple de un recinto } \\
\text { (Figura 3a). }\end{array}$ & $\begin{array}{l}\text { Pequeño recinto habitacional de planta semicircular (?). Test nuclear con } \\
\text { desecho de maíz y residuo cultural sobre el piso. }\end{array}$ \\
\hline C. 5 & PIR-1 & $\begin{array}{l}\text { Estructura simple (Figura } 6 \text { a) } \\
\text { y posible restitución de muros } \\
\text { (Figura } 3 c) \text {. }\end{array}$ & Forma semicircular grande, muro doble derrumbado. \\
\hline C. 6 & PIR-1 & $\begin{array}{l}\text { Estructura simple (Figura 6b. La } \\
\text { flecha indica el monolito). }\end{array}$ & $\begin{array}{l}\text { Forma rectangular grande de ángulos curvados, entrada con dos grandes } \\
\text { bloques, monolito en el ángulo noreste, doble pared. Hay zona de fosos de } \\
\text { ofrenda al este (C-9). }\end{array}$ \\
\hline C. 7 & PIR-3 & $\begin{array}{l}\text { Zona de fosos de ofrendas }(40 \times 40 \mathrm{~m}) \\
\text { al sur del Conjunto } 8 \text { compuesto por } \\
\text { tres geoglifos. }\end{array}$ & $\begin{array}{l}\text { Zona de depresiones circulares y elípticas cubiertas con arena, que contienen } \\
\text { ofrendas de artesanías fragmentadas (test en fosos B } 1 \text { a B 18). }\end{array}$ \\
\hline C. 8 & PIR-7 & Geoglifos. & $\begin{array}{l}\text { Tres geoglifos compuestos por círculos de piedras con acumulamientos en } \\
\text { los núcleos (Test } 1 \text { y } 2 \text { ). El central de mayor diámetro }(9 \mathrm{~m}) \text {. }\end{array}$ \\
\hline C. 9 & PIR-5 & $\begin{array}{l}\text { Zona de fosos de ofrenda } \\
(20 \times 20 \mathrm{~m})\end{array}$ & $\begin{array}{l}\text { Depresiones circulares y elípticas rellenas de arena y ofrendas de artesanías } \\
\text { fragmentadas. }\end{array}$ \\
\hline C. 10 & PIR-1 & Estructura simple. & $\begin{array}{l}\text { Gran recinto rectangular de ángulos curvados rodeado de un círculo periférico } \\
\text { (ordenamiento de piedras sobre la superficie). Hay alineamiento paralelo de } \\
\text { piedras ( } 1.5 \mathrm{~m} \text { ancho) orientado a la entrada del recinto. }\end{array}$ \\
\hline C. 11 & PIR-1 & Estructura simple. & $\begin{array}{l}\text { Gran recinto con restos de círculo periférico asociado a foso circular cubierto } \\
\text { con alineamiento de piedras. }\end{array}$ \\
\hline C. 12 & PIR-1 & Estructura simple. & Situada en depresión. \\
\hline C. 13 & PIR-1 & Estructura simple. & Situada en depresión. \\
\hline C. 14 & PIR-1 & Estructura simple. & Situada en depresión. \\
\hline C. 15 & PIR-1 & Estructura simple. & Situada en depresión. \\
\hline C. 16 & PIR-1 & Estructura simple. & Situada en depresión. \\
\hline C. 17 & PIR-1 & Estructura simple. & Situada en depresión. \\
\hline C. 18 & PIR-1 & Estructura simple. & Situada en depresión. \\
\hline C. 19 & PIR-1 & Estructura simple. & Situada en depresión. \\
\hline C. 20 & PIR-1 & Conglomerado residencial. & Tres recintos conglomerados del patrón Pircas. \\
\hline C. 21 & PIR-1 & Estructura simple. & Situada en depresión. \\
\hline C. 22 & PIR-1 & Estructura simple. & Gran recinto con círculo periférico y fosos cubiertos en su alrededor. \\
\hline C. 23 & PIR-1 & Estructura simple. & \\
\hline C. 24 & PIR-1 & Estructura simple. & \\
\hline
\end{tabular}




\begin{tabular}{|c|c|c|c|}
\hline $\begin{array}{l}\text { Conjunto } \\
\text { (Figura 2a) }\end{array}$ & Sigla & Clase & Descripción \\
\hline C. 25 & PIR-1 & Estructura simple. & $\begin{array}{l}\text { Restos de círculo periférico y alineamiento paralelo de piedras }(1.5 \mathrm{~m} \text { de } \\
\text { ancho por } 20 \mathrm{~m} \text { de largo). }\end{array}$ \\
\hline C. 26 & PIR-1 & Estructura simple. & \\
\hline C. 27 & PIR-1 & Estructura simple. & \\
\hline C. 28 & PIR-1 & Estructura simple. & \\
\hline C. 29 & PIR-1 & Estructura simple. & \\
\hline C. 30 & PIR-2 & $\begin{array}{l}\text { Cementerio con emplantillado de } \\
\text { piedras. }\end{array}$ & Enterramientos en fosos (18 evidencias), Zona de 38 x $17 \mathrm{~m}$. \\
\hline C. 31 & PIR-1 & Estructura simple. & \\
\hline C. 32 & PIR-1 & Estructura simple (Figura 4e). & $\begin{array}{l}\text { Recinto pequeño asociado a círculo periférico, fosos aislados y zonas de } \\
\text { depresiones ( } \mathrm{Z} \text { D). }\end{array}$ \\
\hline C. 33 & PIR-1 & Estructura simple. & \\
\hline C. 34 & PIR-1 & Estructura simple. & \\
\hline C. 35 & PIR-1 & Estructura simple. & \\
\hline C. 36 & PIR-1 & Estructura simple. & Asociado a círculo periférico. \\
\hline C. 37 & PIR-1 & Estructura simple. & \\
\hline C. 38 & PIR-1 & Estructura simple. & \\
\hline C. 39 & PIR-6 & $\begin{array}{l}\text { Cementerio con emplantillado de } \\
\text { piedras (Figura 4a). }\end{array}$ & $\begin{array}{l}\text { Tumbas en emplantillado de piedras (NP) en el núcleo de un gran círculo } \\
\text { periférico }(\mathrm{CP}) \text { en zona de } 25 \times 20 \mathrm{~m} \text { (nueve evidencias funerarias). }\end{array}$ \\
\hline C. 40 & PIR-8 & Geoglifo. & Un círculo con promontorio en el núcleo, al suroeste de PIR-6. \\
\hline C. 41 & PIR-1 & Conglomerado residencial. & Varios recintos aglomerados. \\
\hline C. 42 & PIR-1 & Estructura simple. & \\
\hline C. 43 & PIR-1 & Estructura simple. & \\
\hline C. 44 & PIR-1 & Estructura simple. & \\
\hline C. 45 & PIR-1 & Estructura simple. & $\begin{array}{l}\text { Depresión habitacional con montículos en los contornos, sin acomodo de } \\
\text { piedras. }\end{array}$ \\
\hline C. 46 & PIR-1 & Estructura simple. & Asociado a posibles fosos de ofrendas. \\
\hline C. 47 & PIR-1 & Estructura simple. & Restos de círculo periférico. \\
\hline C. 48 & PIR-1 & Estructura simple. & \\
\hline C. 49 & PIR-1 & $\begin{array}{l}\text { Conglomerado residencial } \\
\text { (Figura } 4 \mathrm{~b} \text { ). }\end{array}$ & $\begin{array}{l}\text { Dos recintos aglomerados con planta típica rectangular con ángulos curvados. } \\
\text { Se aprecian cuatro monolitos típicos en los muros y tres fosos circulares en } \\
\text { el borde este. }\end{array}$ \\
\hline C. 50 & PIR-1 & Estructura simple. & \\
\hline C. 51 & PIR-1 & Estructura simple. & \\
\hline C. 52 & PIR-1 & Estructura simple. & Uso de grandes bloques. \\
\hline C. 53 & PIR & Conglomerado residencial. & Similar a la planta del C 49. \\
\hline C. 54 & & Estructura simple. & \\
\hline C. 55 & & Estructura simple. & \\
\hline C. 56 & & Estructura simple. & \\
\hline
\end{tabular}

Cuadro 1. Catastro de estructuras y sitios interrelacionados de los dos focos. 


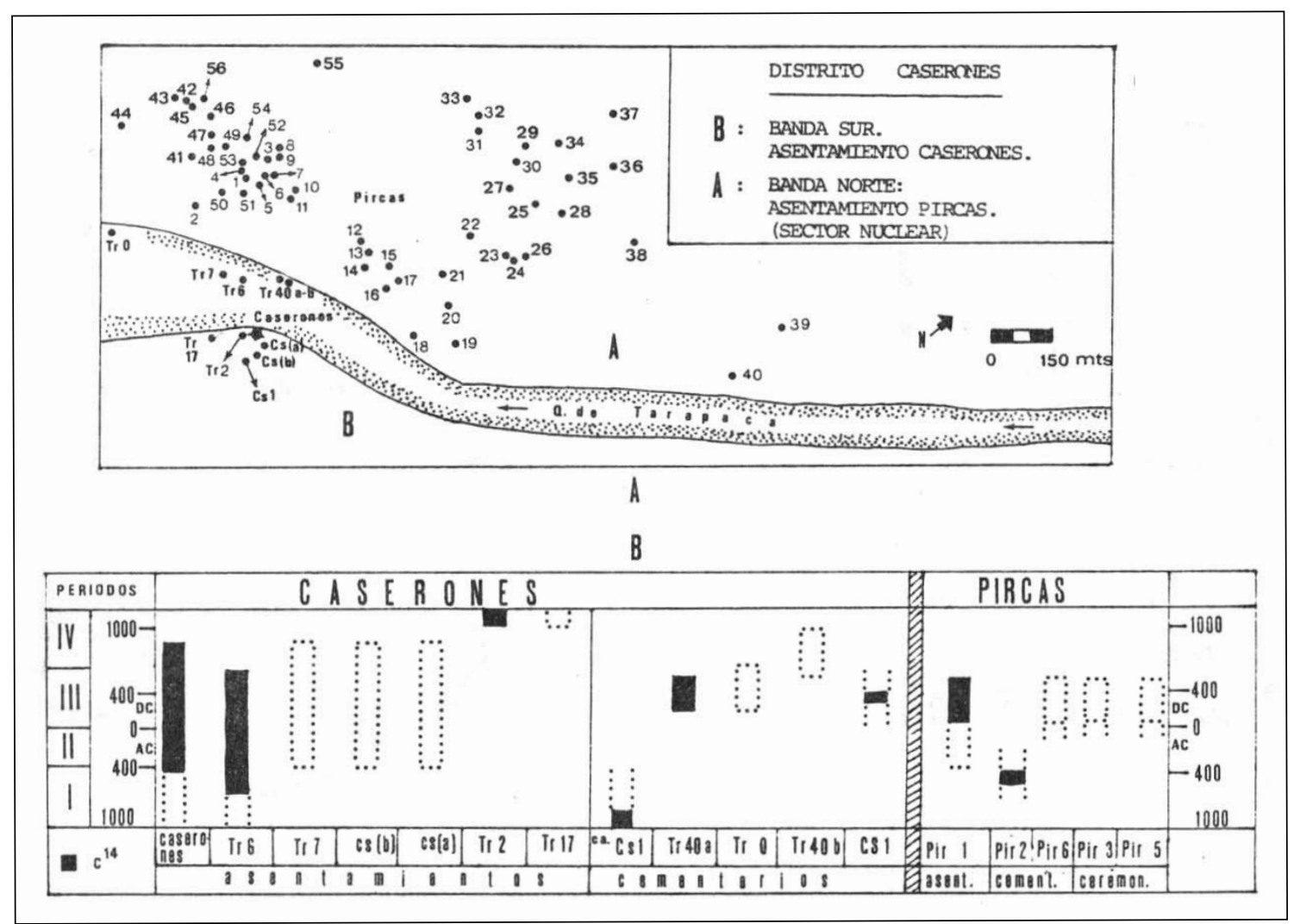

Figura 2. Distrito Caserones. Asentamientos Pircas y Caserones.

Los 56 conjuntos o evidencias culturales individualizadas puede dividirse en las siguientes categorías funcionales:

a) Estructuras habitacionales y de servicio que configuran la base formal del tejido aldeano disperso del asentamiento Pircas 1 (PIR-1).

b) Cementerios con o sin círculo periférico (alineamiento de piedras) que constituyen las zonas de enterramientos del poblado. Se han reconocido dos hasta ahora, bajo la denominación de Pircas 2 y 6 , respectivamente.

c) Zonas de fosos socavados de ofrendas, concentradas cerca de las estructuras, en espacios eriazos destinados a actividades ceremoniales, a juzgar por el registro de ofrendas "matadas" o fracturadas intencionalmente durante su depositación (Pircas 5 y 3, respectivamente).

d) Geoglifos u ordenamientos de piedras con diseños de círculos con promontorios de piedras en el núcleo, líneas paralelas, aserradas, líneas y círculos simples, registrados en distintos sectores de la zona ocupacional. De estos sólo se han dispuesto dos conjuntos en el mapeo de campo (el plano topográfico in extenso, con el total de conjuntos culturales, se encuentra en elaboración).

\section{Análisis de los rasgos culturales de superficie}

Al observar los dos focos revisados con mayor atención surgen cinco clases de evidencias de restos culturales de superficie suficientemente distribuidos, que de acuerdo a los test estratigráficos son componentes del Complejo Cultural Pircas:

a) Fragmentación exclusiva de cerámica café burda alisada, asociada a recintos y zona de fosos, con baja frecuencia en relación al poblado de Caserones.

b) Zonas de talleres con preformas y artefactos pesados de basalto, sílice e ignimbrita locales, preparados con burda percusión: choppers, bifaces, percutores, 


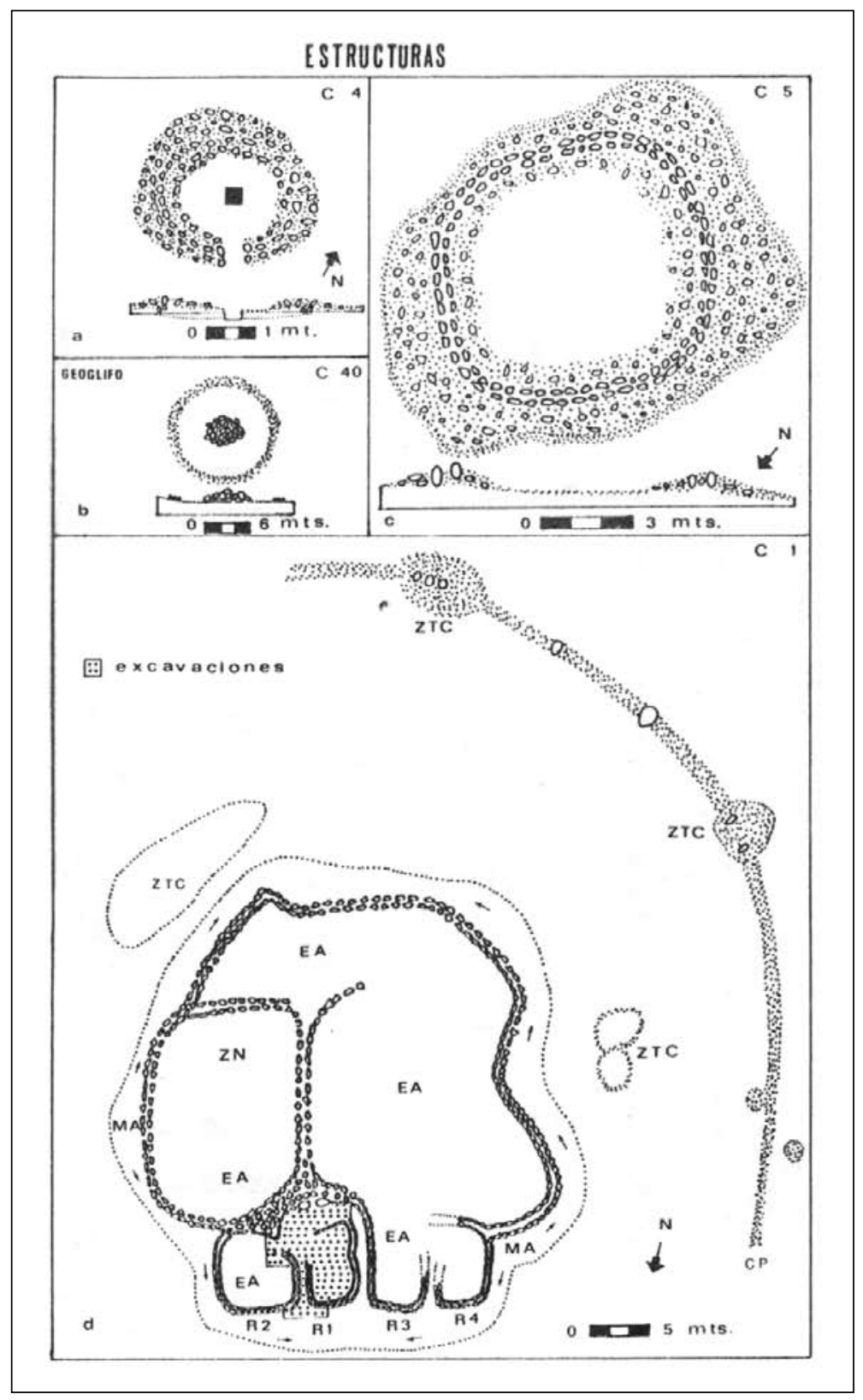

Figura 3. Estructura y geoglifo.

raspadores, cepillos, cuchillos y raederas. No se advierten puntas de proyectiles ni implementos de molienda. Estas zonas de talla se vinculan tanto con los interiores de los recintos y los bordes inmediatamente periféricos. En reversa a la cerámica, el registro de núcleos, preformas y burdos artefactos percutidos son más comunes. El registro de artefactos terminados derivados de las preformas se han encontrado en la estratificación de los recintos excavados, por lo que esta alta actividad de talla lítica es parte del contexto cultural Pircas (hay artefactos burdos usados sobre madera).

c) Presencia relativa de conchas y espinas de peces del Pacífico.

d) Ubicación de bloques líticos de estatus (rocas verdes), con modificaciones por percusión, 


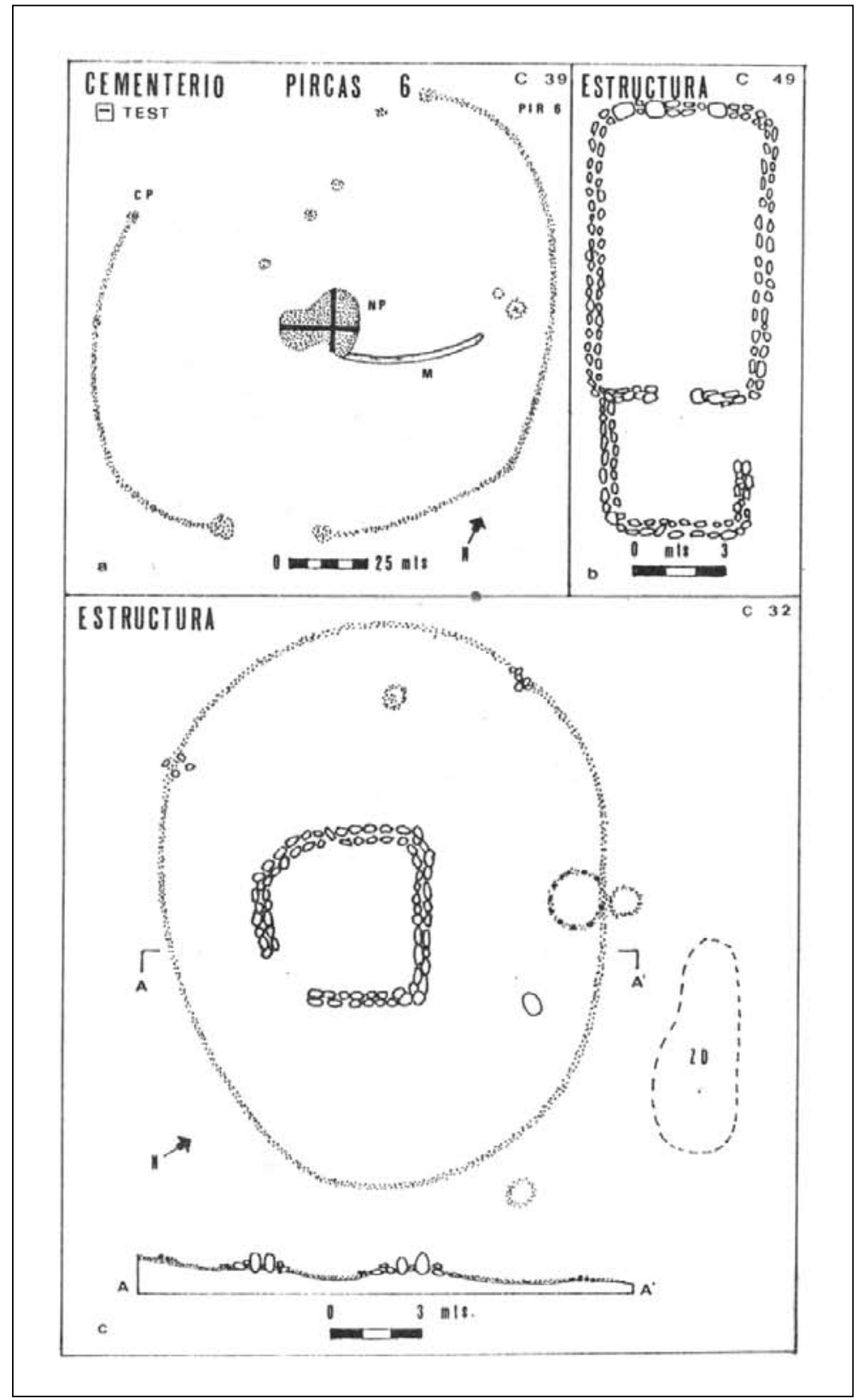

Figura 4. Cementerio Pircas 6.

dispuestos dentro de recintos o en sus contornos, vinculados a sus desechos de talla correspondientes.

e) Disposición de grandes bloques canteados o seleccionados por sus formas alargadas a modo de signos visibles o monolitos simples, empotrados en los muros o volteados en los espacios interiores o exteriores de los recintos.
Análisis de las estructuras

De acuerdo a la acción de ráfagas de arenas del oeste se ha establecido un avance de dunas en donde cada estructura ha intensificado su acumulación. A pesar de esto, los muros son identificables, tanto por sus dobles hiladas originales, como a través de sus restos abatidos, configurando en el primer caso semicírculos y rectángulos de ángulos curvados y 


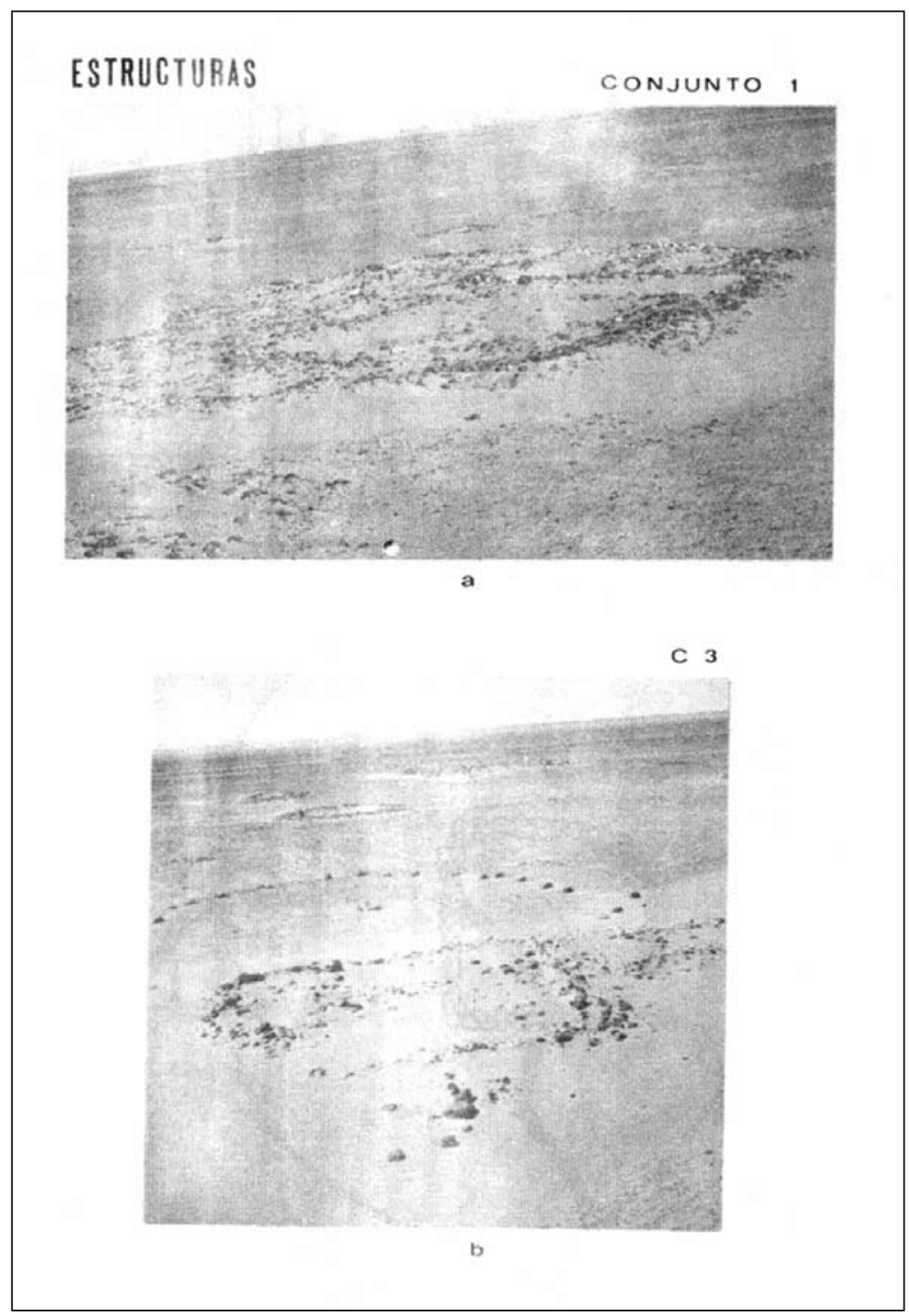

Figura 5. Estructuras del Conjunto 1.

en el segundo caso, zonas anchas de emplantillados de piedras y leves montículos cubiertos de bloques y arena (Figura 6a). La ausencia de bloques en el centro y el registro de pisos con desechos residuales de actividad humana, habla a favor de su carácter habitacional. Esta situación no es válida en los geoglifos, donde en reversa, no hay pisos socavados ni restos de depósitos orgánicos, porque los leves alineamientos y acumulamientos de piedras fueron dispuestos sin técnicas de muros sobre la superficie no modificada (Figura 3b).

Aunque los muros están derrumbados hay casos donde se aprecian visibles sin un pegamento evidente. La técnica usual corresponde a dos hileras de bloques de tendencia a disposiciones verticales, dejando en su intermedio desechos de actividad (residuos vegetales, líticos y arena) y al empotramiento de bloques más grandes en las zonas de entrada. Para este efecto se utilizaron materiales locales de basalto, granito e ignimbrita para ordenar muros anchos de 20 a $50 \mathrm{~cm}$, sin enfatizar el uso de postes de árboles locales como ocurrió en Caserones. Cada recinto puede tener divisiones adosadas más pequeñas (Figura 4b), pero fuera de algunos conglomerados mayores, el patrón más usual lo constituyen los recintos simples y aislados (Figura 4c), los cuales predominan mientras más se alejan de los núcleos más densos y complejos. 


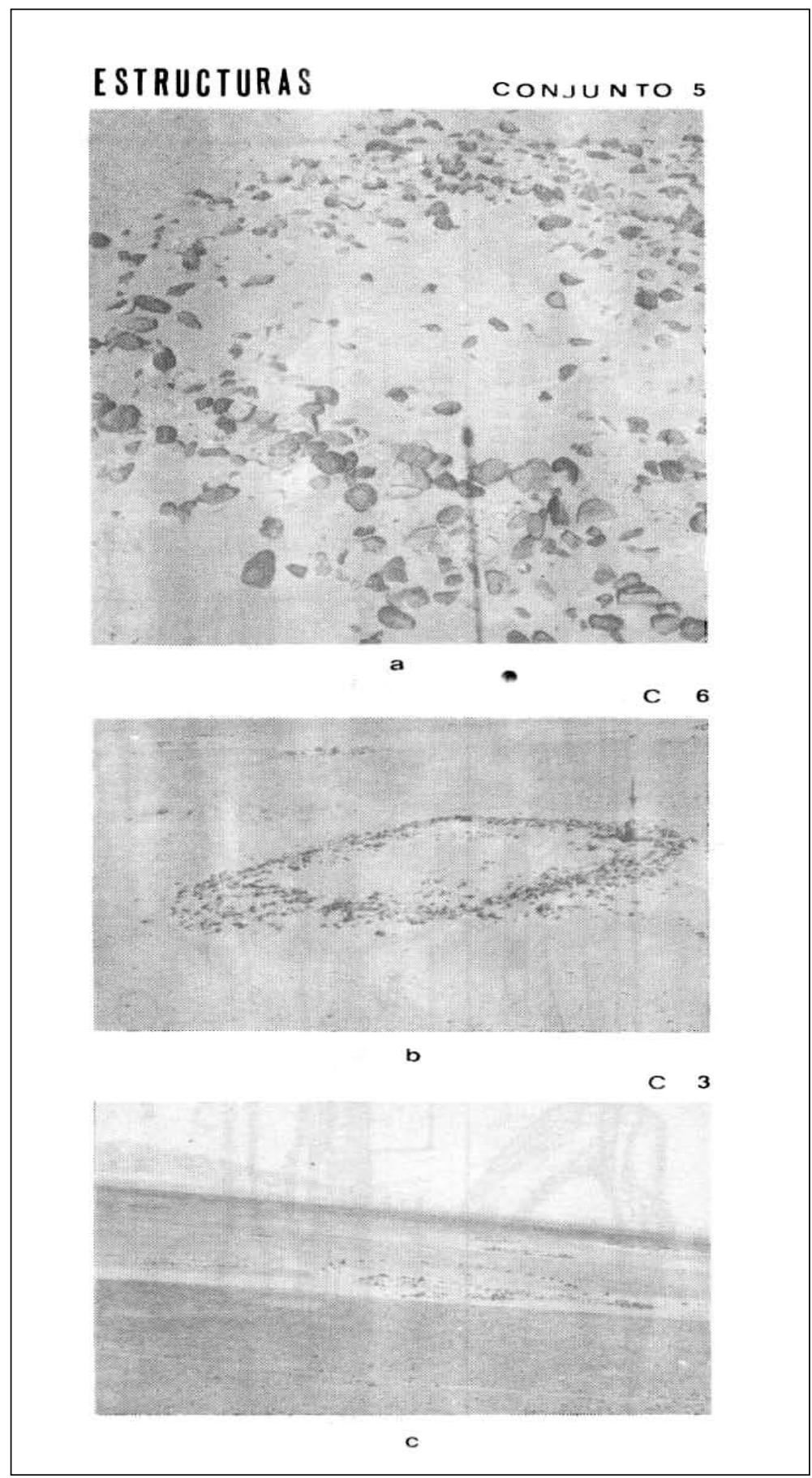

Figura 6. Estructura del Conjunto 5.

Las estructuras habitacionales pueden estar aglomeradas (Figura 3d), pero aún pueden vincularse con zonas de ceremonias tal como se desprende por la cercanía a fosos de ofrendas (Figura 6b). Al tanto que otros recintos grandes de planta subrectangular presentan uno o más monolitos que se fijaron en los muros (Figura 4b). Tal patrón de ceremonias en torno a monolitos se hace más elocuente en los conjuntos $\mathrm{n}^{\mathrm{os}} 6,2,49$ y en el $\mathrm{n}^{\mathrm{o}} 3$, donde las estructuras residenciales se adjuntan a un gran hemiciclo 


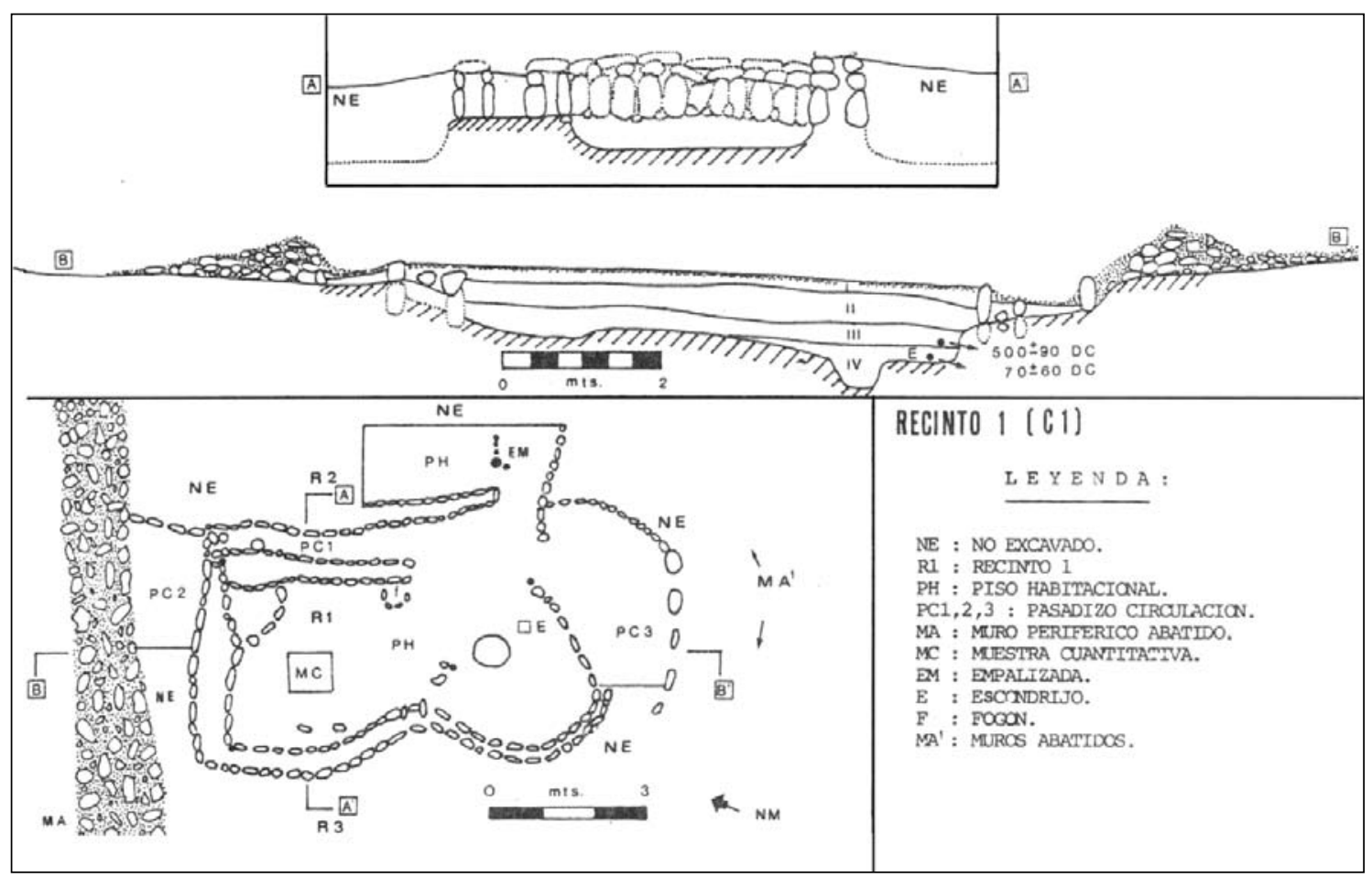

Figura 7. Recinto 1, Conjunto 1.

de bloques alternados que equidistan del centro donde se sitúa un bloque notable (Figura 5b). Otros ordenamientos de pequeños círculos de piedras en fosos o en planos hablan a favor de un énfasis en actividades no domésticas, a través de los espacios exteriores a los recintos.

En relación a lo anterior se distingue a lo largo del asentamiento una constante práctica de limpia de territorios electos para fines residenciales y ceremoniales. Las piedras recogidas se han acumulado en sectores interrecintos o se han configurado en geoglifos y más comúnmente en grandes círculos periféricos que rodean los recintos y aún un cementerio. El registro de 9 estructuras rodeadas de círculos en distintos y distantes lugares del poblado otorgan una modalidad ceremonial o de límites de territorios familiares, lo cual tipifica al asentamiento. Esto ocurre tanto en pequeños recintos (Figura 4c), como en el conjunto $\mathrm{n}^{\mathrm{o}} 1$ o de mayor aglutinamiento de recintos, en donde se advierte parte del círculo con segmentos perturbados por el tráfico contemporáneo (Figura 3d). El ordenamiento de círculos ocurre además en uno de los cementerios correspondiente a Pircas 6 (Figura 4a) y en los geoglifos propiamente tales (Figura 3b). Definitivamente esta singular situación tipifica a Pircas y le da coherencia e identidad a la distribución dispersa del asentamiento con recintos dispuestos en un amplio relieve planiforme.

\section{Las excavaciones de prueba}

Durante 1982 y 1983 se han llevado a cabo los primeros tests destinados a evaluar el contenido socioeconómico de los depósitos de los recintos y la identificación del contexto cultural, que eventualmente de acuerdo al examen visual no guarda relación con otros asentamientos tempranos de Área Centro Sur Andina.

a) Geoglifos. En una leve colina que domina el núcleo habitacional principal (al noreste del Conjunto 1), se identifican tres geoglifos contiguos (círculos con promontorios), siendo el central de mayor diámetro (9 m). Dos calicatas de $0.5 \mathrm{~m}^{2}$ demuestran carencia de restos orgánicos y la inmediata disposición de las piedras sobre la superficie no alterada por actividad humana. Este tipo de geoglifo se vincula directamente con ceremonias estables en el poblado y difiere de los diseños clásicos o tardíos reconocidos como indicadores de ceremonias durante el tráfico de caravanas de llamas y que existen con alta frecuencia 


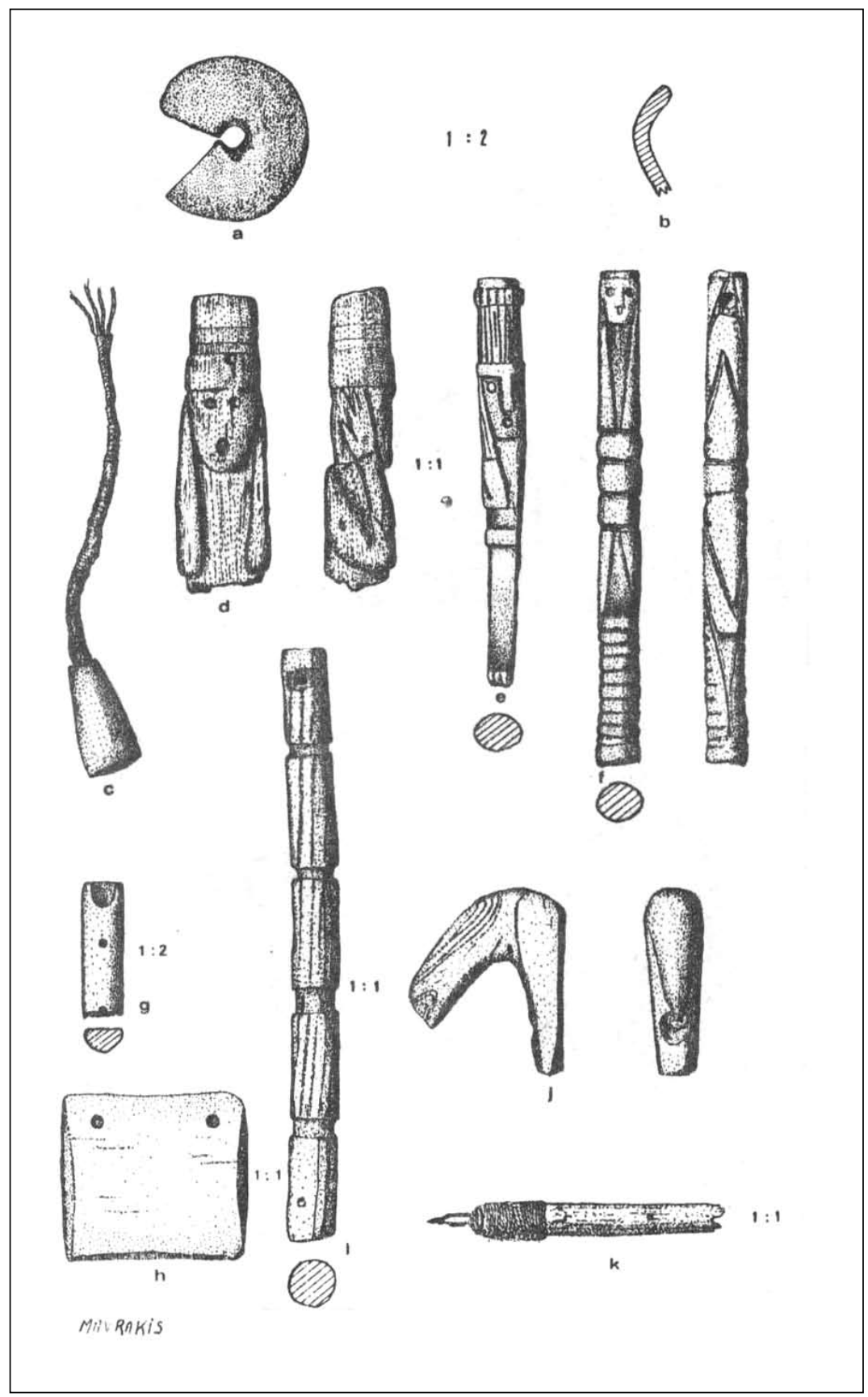

Figura 8. Contextos estratigráficos del Recinto 1-2 (Pircas-1): a) Tortera de fragmento cerámico reutilizado (E-III), b) Típico borde de cerámica monocroma alisada (E-I) y c) Adorno de madera con colgante de cuerda (Test 1/III-b; d) Fragmento de tallado antropomorfo en madera (C-1/R-2/III); e) Fragmento de tallado antropomorfo en madera con incrustación de malaquita en los ojos (C-1/R-2/IV); f) Tallado antropomorfo en madera, vista anterior y posterior, con orificio superior para suspensión (C-1/R-1/III); g) Fragmento de flauta en hueso (R-1/Test 1/IIl); h) Tallado plaquiforme en madera con dos orificios de suspensión (Test 1/III-b); i) Tallado acinturado de madera (R-1/C-1/ III); j) Tallado en madera ornitomorfo (?) o gancho de propulsor con perforación de amarre o suspensión (R-2/C-1/III); k) Microperforador enmangado con lasca de obsidiana (R-1/C-1/III). 


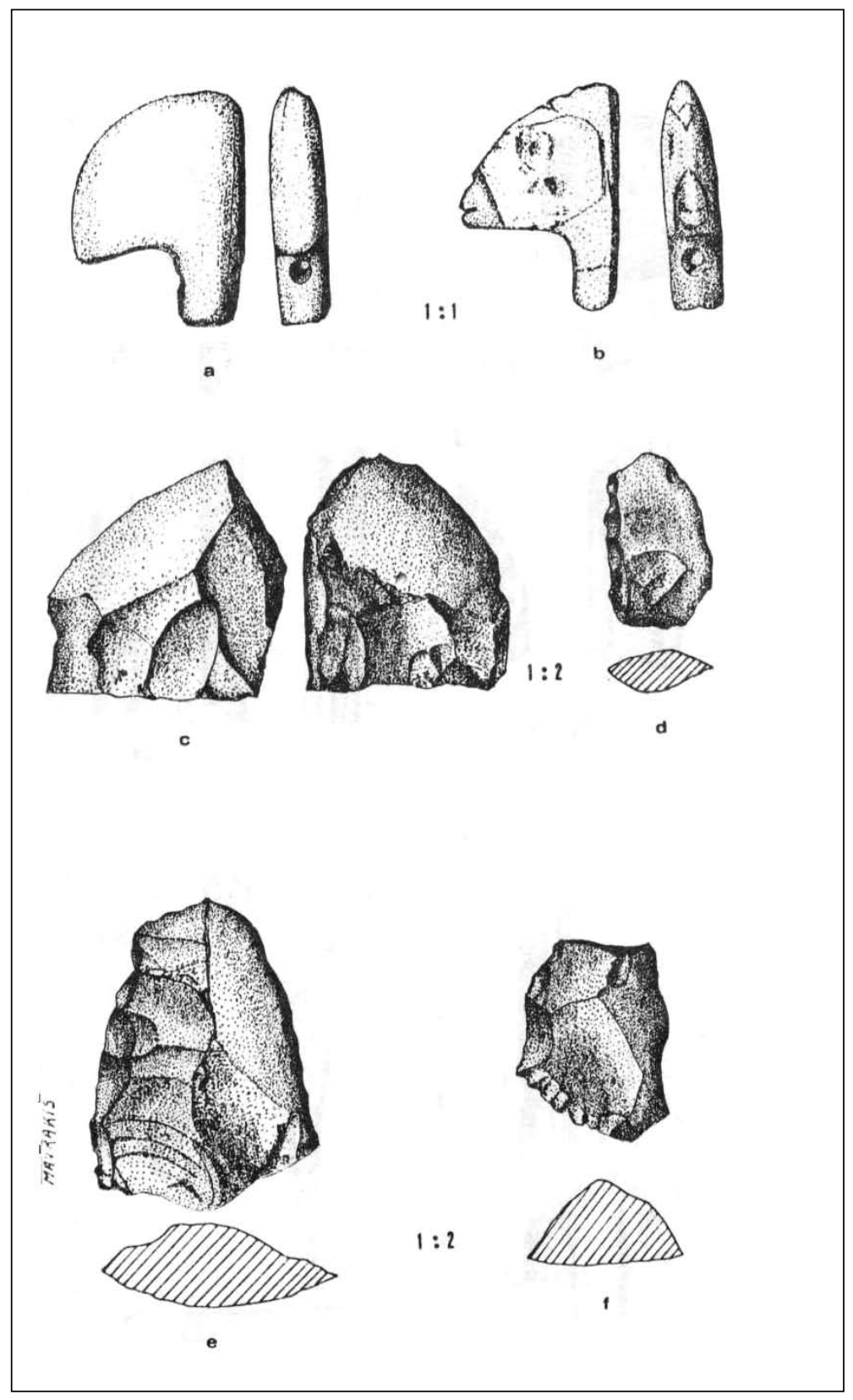

Figura 9. Registros comparados del asentamiento Pircas: a) Tallado en madera ornitomorfo como pico de guacamayo, con perforación (Pir1/R-2/III); b) Tallado en madera con perforación similar, con diseño de camélido a juzgar por dos leves elevaciones como orejas (Pir-3/D-14); c) Núcleo basáltico de uno de los talleres del exterior del conjunto 1 (Pir-1 Sup.); d) Raedera basáltica (Pir-1/R-2/C-1/IV); e) Cuchillo-raedera basáltica en el interior del conjunto 1 (Pir-1, Sup.); f) Raedera basáltica de dorso alto en el interior del conjunto 1. 
en la banda sur de la quebrada, entre Caserones y San Lorenzo de Tarapacá.

b) Fosos de ofrendas. Llama la atención el hecho de que en torno a estos geoglifos no se hayan construido habitaciones. A través del espacio eriazo que desciende en la pendiente hacia las estructuras bajas tampoco existen viviendas pero sí se verifican leves depresiones con rellenos diferenciados de arena eólica que parecieron ser en primera instancia fosos funerarios. Esta amplia extensión de leves depresiones fue testificada a través de 18 controles en distintas situaciones. Este examen demostró que todos son fosos excavados con formas circulares y elípticas, en profundidades de 20 a $100 \mathrm{~cm}$, con diámetros fluctuantes entre 25 a $150 \mathrm{~cm}$. En sus paredes y fondos compactos no había trazas de descomposición de cuerpos humanos. En ningún caso fueron preparados para funciones funerarias. Sus contenidos guardan relación con la depositación de manufacturas: cerámica café alisada, capachos, cestos, hilos, cucharas, maíz, porotos, algarrobo, etc. Tanto la cerámica, tejidos, capachos, phaseolus, maíces y talla en madera de figurinas antropomorfas y ornitomorfas (Figura 8f-j), son similares a los registros datados en el Conjunto 1 o conglomerado residencial de mayor densidad emplazado en el sector aledaño y todos estos materiales aparecen ciertamente fragmentados.

Al vincular este campo de ofrendas (piezas "matadas") con los geoglifos y los contextos culturales recuperados en los recintos del Conjunto 1 , se sugiere que estas tres clases de sitios presentan componentes culturales similares como partes sustanciales del asentamiento Pircas.

Los tests en otros seis fosos similares, con gran cantidad de fragmentos de cerámica del patrón Pircas, esta vez en un espacio eriazo emplazado al este del conjunto habitacional 6 , equivalente al gran recinto con un monolito notable (Figura 6b), hablan a favor de la existencia de otros campos de ceremonias. En esta oportunidad, el alto número de fragmentos cerámicos en algunos fosos más amplios no puede asignársele a depresiones de cocina $\mathrm{u}$ hornos al aire libre (ausencia de restos de fogones o alteración por alta temperatura). Más bien la evidencia habla a favor del socavado de fosos para depositar desechos de cerámica que no siempre provienen de un mismo tiesto, sino de múltiples, fracturados por uso fuera de la zona. Aparentemente se ven como depósitos de cerámica fragmentada y desechada, como reservorio de desperdicios con cerámica dominante. No obstante, si los depósitos de esta segunda zona de ofrendas (Conjunto 9) repiten el caso del campo de ofrendas del Conjunto 7, la explicación podría ser más ceremonial que doméstica. Para ampliar esta indagación se revisarán espacios exteriores que hayan contenido algún tipo de actividad con uso de cerámica. En efecto, estos tests no fueron muy explícitos en términos de otras manufacturas fracturadas (capachos, cestos), provenientes de piezas enteras, tal como lo registramos en la zona anterior (Conjunto 7), junto a los geoglifos.

c) Estructuras exóticas. El Conjunto 2 representa a dos acumulamientos de piedras y arena paralelos con $70 \mathrm{~m}$ de longitud máximo por un ancho promedio de $2.5 \mathrm{~m}$. Se advierten como dos grandes semiarcos cuya acumulación de arena y emplantillado de piedras enfatiza su carácter de promontorios estrechos, largos y curvados. Hay evidencia de pequeños recintos y de un muro del patrón Pircas en donde se adosaron reducidas estructuras alternadamente. Obviamente que no corresponden al tipo usual de recinto habitacional. Hay restos de talla de piedras verdes de estatus y grandes monolitos abatidos. Como entre ambas estructuras se localiza un espacio central, es probable que desempeñó alguna función ceremonial. Tres calas practicadas en distintos lugares demuestran que bajo los muros abatidos hay desechos de sorona, maíz y fragmentos de cerámica del patrón Pircas. Por otra parte, la presencia de desecho vegetal podría establecer una función distinta vinculada con labores agrarias, puesto que las cosechas debieron trasladarse desde el fondo del valle al plano alto, justo donde estas estructuras limitan con el borde de la quebrada. De uno u otro modo su conexión con el poblado queda fuera de duda, a pesar de su forma exótica.

d) Estructura residencial simple. Se seleccionó un recinto simple con la típica técnica de doble pared confundida con un emplantillado producto de su derrumbe (Figura 3a). Corresponde al Conjunto 4 en donde se practicó un test central de $0.5 \mathrm{~m}^{2}$, el cual demostró que bajo $15 \mathrm{~cm}$ de arena eólica se extendía un piso compacto habitacional con desechos de maíz, cerámica café fragmentada del patrón Pircas (superficie alisada y escaso baño rojo con huellas de brochado, residuos de cañas, fibras y vainas de algarrobo, asociados a desechos de talla de basalto). De acuerdo a estas evidencias se propone que las estructuras de este tipo son viviendas con componentes de indudable filiación Pircas. 
e) Conglomerado residencial. Para evaluar el rol de los conjuntos de estructuras abigarradas se escogió el Conjunto 1, que corresponde al mayor conglomerado registrado en la zona (Figura 3d). Se advierte como un gran emplantillado de piedras rodeado de arena eólica (Figura 5a).

El survey de superficie registró escasa cerámica café alisada y abundante desecho de talla de basalto, sílice e ignimbrita, incluyendo artefactos morfológicamente bien definidos (Figura 9c-e). Se constató la técnica de doble pared en cuatro recintos (1-2-3-4), en el borde norte y en ciertas prolongaciones expuestas al sureste en tanto que en el núcleo hay grandes recintos cuyas paredes laterales marcan el límite del avance de dunas. En algunos espacios interiores erosionados se ubicaron sectores de talla lítica $(Z$ T). Sin embargo, la presencia de pequeños talleres y cerámica fragmentada propiamente tales (ZTC) se aprecia en los contornos del límite sur y suroeste y en los bordes de las hileras de piedras que configuran el gran círculo periférico (CP) del cual sólo resta un gran sector occidental (ver Figura 3d). El conglomerado tiene sus límites bien amurallados, pero sus interiores están cubiertos de estructuras abatidas (EA), por lo que es difícil definir sus características estructurales. Al igual que en otros casos, este círculo está rítmicamente engrosado con leves acumulamientos de piedras y fosos restringidos de funciones no identificadas.

Se seleccionó un sector correspondiente al recinto 1 , donde se apreciaban estructuras bien definidas por muros que sobresalían levemente en la cubierta de arena, en el borde $\mathrm{M}$ del conglomerado (ver Figura 3d). La excavación se centró en el recinto que presentaba un muro ondulado al oeste y un sector más alterado en la zona de acceso desde el núcleo a juzgar por el empotramiento de dos grandes bloques. Al observar el plano de planta se desprende que la excavación esclareció las siguientes subunidades funcionales (Figura 7):

a) El desarrollo de un muro periférico derrumbado como emplantillado, que protege al asentamiento del avance de dunas y enfatiza el límite del territorio ocupado (MA).

b) Se definió un tipo de recinto que parece ser de un "patrón en ocho" o simplemente uno solo con paredes más curvadas al oeste (R-1).

c) Se distinguieron los recintos laterales contiguos (R-2-3) de los cuales sólo se identificó la zona de comunicación entre R-1 y 2, donde se dispuso una empalizada de postes y cañas sin otros materiales adicionales (E).

Se puede señalar que los lugares dispuestos para la construcción de los recintos fueron inicialmente socavados (ver perfil AA' en Figura 7). En los bordes de la depresión se prepara una bancada leve donde se empotraron bloques verticales pegados con residuo vegetal, para evitar el ingreso de arena y ajustar los bloques entre sí. Sobre esta hilada se dispusieron bloques horizontales para presionar y compactar el muro evitando además el ingreso de arena. Más arriba se localizaron piedras disgregadas y abatidas del mismo muro. Las paredes son de doble hilada con sus interiores rellenos de basura, arena, desecho de talla, residuos vegetales, etc. El piso habitacional es semisubterráneo o socavado y representa una base compacta $(\mathrm{PH})$ con evidencia de un foso como bodega y un escondrijo (E) con equipos ceremoniales. Algunos bloques aislados para labores domésticas, fogones (F) en ángulos y una pequeña división angular esquinada (NE) completan el registro. En tres ángulos esquinados del recinto y en la parte superior de los muros se detectaron restos de postes delgados para la sustentación de techo liviano como ramada. $\mathrm{Al}$ respecto hay tres postes de un total probable de cuatro, que en cada ángulo sustentaban los bordes del techo, de una manera muy distinta al patrón de múltiples y gruesos postes de Caserones. También se identificó una red de pasadizos de circulación (PC 1, 2, 3), de ancho restringido que se disponen en los contornos altos que rodean al R-1. Su carácter está dado por la presencia de un piso bien transitado y compactado que como delgada pasarela recoge el espacio exterior al interior. Un acceso principal desde el núcleo del conglomerado se identificó en el extremo sur de la zona excavada. Se trata de una hilera de bloques donde se destacan dos muy voluminosos que marcan el principal acceso al pasadizo alto del sur a partir del cual se ingresa al recinto, pero esta situación aún no ha sido clarificada.

El recinto 1 o principal y parte del R-2 contiguo y los leves depósitos de los pasadizos circundantes fueron excavados. Los acumulamientos de desperdicios más densos se establecieron en el recinto 1 o principal (ver perfil B-B en Figura 7).

Un gran depósito con restos culturales, abundante desecho de maíz y densos acumulamientos de arena eólica fueron detectados desde el final al comienzo de ocupación, por lo que se desprende que el recinto 
se encontraba casi totalmente cubierto antes de la excavación,

\section{La evaluación estratigráfica del Conjunto 1}

\section{a) Zona de pasadizos (PC 1)}

Estrato I: Relleno de arena eólica y residuos de cañas de maíz.

Estrato II: Abundante desecho de maíz y escasa arena eólica.

Estrato III: Escasos restos de maíz, arena eólica y base con sedimento blanquecino de la descomposición del depósito local.

En el pasadizo junto al muro periférico de protección (PC 2) la ocupación fue más leve con un estrato básico sobre el piso. Por otra parte el pasadizo 3 (PC 3) contenía escasa acumulación.

b) Zona del Test-2 (Recinto 2). Se constató una parte del recinto contiguo (R-2) a través de un depósito de desperdicios sobre el piso básico, en donde se empotró un poste grueso y cañas (empalizada), cuya función no se ha esclarecido, ya que aún no se termina la excavación de dicho recinto.

c) Zona habitacional del Recinto 1 (R-1). Se identificaron tres estratos: I, II, III, de manera generalizada y un IV en la parte más baja del recinto:

Estrato I: Arena eólica, escasa basura y restos culturales; residuos escasos de maíz.

Estrato II: Aumento de desecho de maíz (hojas, granos, mazorcas, cañas y raíces) y residuo cultural: cerámica, tallas en madera, hilos, etc.

Estratos III y IV: Máximo incremento de restos de maíz y residuos culturales. Un bloque cúbico de desecho de maíz del orden de 70 x 80 x $30 \mathrm{~cm}$ fue recuperado como muestreo para análisis cuantitativo (MC) del potencial agrario en los primeros episodios del poblado.

El estrato IV es la base del III y se ha segregado por su concentración en el sector más bajo del perfil pero no significa un cambio significativo (los estratos IV y III fueron datados entre los 70 a 500 años DC). Un conjunto de artefactos diagnósticos de este perfil demuestra por ahora el carácter poco común de estos indicadores (Figuras 8 y 9). El total de rasgos cuantificados y cualificados serán descritos en otro informe dedicado exclusivamente al Conjunto 1 (ver Figura 7).

Los contextos culturales recuperados resultaron ser muy homogéneos a lo largo del depósito. Hay una clara continuidad de actividades alteradas solamente por etapas de mayor ingreso de arena, lo cual en esta zona no es un hecho dependiente exclusivamente de períodos de abandonos temporales. El registro de cilindros antropomorfos (ver Figura 8f), desde el estrato IV al I, señala esta persistencia. El carácter de residencia está dado por el registro de fogones, por la acumulación de desperdicios alimentarios y manufacturas (adornos, fragmentos de cerámica, tejidos, hilos). Los restos de material vegetal son muy diversos pero con un dominio impresionante de maíz (Zea mays), bastante algarrobo (Prosopis juliflora), escasos pallares (Phaseolus lunatus) y semillas de algodón (Gossypium sp.). Escasean los implementos de molienda, residuos óseos de fauna y coprolitos de llama. La presencia de artefactos líticos similares a tipos "precerámicos" es también elocuente (ver Figura 9d), pero no son tan frecuentes como en los registros superficiales.

\section{Los tests funerarios}

A través del reconocimiento se identificó un sector con emplantillado de piedras (Conjunto 30), hoquedades leves y escasos restos óseos expuestos. Se trata del sitio Pircas 2, conformado por enterramientos en fosos circulares en donde se registraron 18 tumbas, la mayoría perturbadas a raíz de su situación junto al terreno planiforme de mayor tráfico contemporáneo (Tarapacá-salitreras). Los estudios en curso (Standen Ms) señalan la presencia de grandes cestos coiled de fibras, plumas tropicales, restos de turbantes, mantos "felpudos", etc., de filiación cultural temprana. $\mathrm{Al}$ observar la Figura 2a se advierte que este cementerio se sitúa entre recintos típicos del patrón Pircas (ver Conjunto 30). Una datación del orden de los 480 años $\mathrm{AC}$ establece un primer hito cronológico.

Un segundo sector funerario se identificó en el Conjunto 39 (Pircas 6), a través de un emplantillado de piedras (NP) con restos óseos expuestos y cerámica del patrón Pircas en mayor cantidad que los escasos fragmentos del sitio anterior. En Pircas 6 se enfatiza más la aplicación de baños rojos en superficies café alisados y brochados. Corresponde a un cementerio muy singular por configurar 
deliberadamente el núcleo pedregoso (NP) como punto central de un gran círculo periférico $(\mathrm{CP})$ a base de alineamiento de piedras superficiales (ver Figura 4a), asociado a fosos, reducidos círculos y una marca como geoglifo longitudinal (M). El test recientemente realizado demostró también la disposición de nueve cuerpos en fosos socavados, de los cuales sólo uno o dos se encontraban en condiciones de regular preservación. Aún no se han constatado ofrendas culturales suficientemente diagnósticas, pero el registro de un madero fragmentado, tallado como un cilindro con varios acinturamientos rítmicos similar a otro espécimen del recinto excavado o Conjunto 1 (ver Figura 8i) y los materiales culturales de superficie (cerámica café alisada), permiten a lo menos señalar que este cementerio pertenece al asentamiento. Un aspecto peculiar de este sitio es que junto a la zona de enterramiento se detectó un piso habitacional socavado con depresiones como bodegas y huecos de postes llenos de coprolitos, eventualmente como parte del patrón Pircas, pero su exacta separación de alguna probable reocupación se encuentra en proceso de análisis (el espacio habitacional no perturbó la zona de enterramientos, con la cual claramente limita).

\section{La situación cronológica}

Tanto el patrón de asentamiento disperso, la peculiar morfología estructural, los rasgos culturales de superficie y los contextos sellados no tienen contrapartes a nivel de comparaciones específicas en el Area Centro Sur Andina. El patrón disperso, la idea de monolitos y el estructuramiento subrectangular sugirió un posible correlativo con el poblado de Alamito (Núñez Regueiro 1971), pero los recintos y los contextos culturales son sumamente distintos. La vivienda de Alamito tiene una entrada tan compleja como su propio patrón de ordenamiento y litoescultura sofisticada, que a pesar de las relaciones sincrónicas no se homologan in estricto, aunque comparten un manejo disperso del espacio que otorga una relación de aparente similitud. Algo similar ocurre con el temprano asentamiento de Tafi (disperso, cerámica monocroma y monolitos sofisticados), pero no existe una identidad en rigor (González y Núñez Regueiro 1962).

Se asumía que la presencia de cerámica alisada monocroma dominante podía establecer una data más o menos temprana, pero fuera de esta intuición no se contaba con un cálculo previo confiable. La vinculación de los monolitos con el altiplano estimula ciertas sugestiones que se discutirán en otra oportunidad.

Para determinar una primera aproximación cronológica se obtuvieron muestras del perfil estratigráfico del R-1 del Conjunto 1 (ver Figura 7). La primera muestra de carbón se obtuvo de un fogón ubicado sobre basura vegetal inmediatamente sobre el piso del recinto 1 . La datación (N-4368) corresponde a 1880 $\pm 60 \mathrm{AP}$ (vida media de 5568 años), equivalente a $70 \mathrm{DC}$, dando un valor temporal coherente para el sector nuclear del estrato IV asociado a maíz, cerámica café alisada, algarrobo y tallados cilíndricos antropomorfos de madera (ver Figura 8f). Es evidente que el fogón estuvo activo en este tiempo y obviamente más antes se construyó el recinto. Una depresión leve en el piso (ver Figura 7e), situado cercanamente a la muestra, contenía una bolsa con utensilios litúrgicos, uno de los textiles policromos presenta un diseño del sacrificador (diseño antropomorfo con colmillos cruzados), asociado a múltiples tallados con cilindros antropomorfos y útiles de talla que pertenecieron a algún personaje vinculado con imágenes religiosas de prestigio en el área. Las basuras que cubrían este escondrijo (E) son sincrónicas a esta datación, de modo que este contexto ceremonial es cercano a los $70 \mathrm{DC}$, pero nunca posterior a esta fecha.

Otra datación (Beta-5461) corresponde a una muestra de coprolito con semillas de algarrobo, asociada a vainas completas situadas entre la basura de la base del estrato III. Es decir, se ha fechado un episodio posterior al anterior, pero dentro de un régimen de sucesivas capas de desechos de maíz, datado a los $1450 \pm 90 \mathrm{AP}$ (de igual vida media al anterior), equivalente a $500 \mathrm{DC}$.

Finalmente, otra reciente datación (gentileza de M. Allison) proviene del cementerio Pircas 2 (T1), de un tejido muscular muestreado por M. Allison y V. Standen. El resultado es de 2420 \pm 80 AP (I-13.228), equivalente a 480 años $\mathrm{AC}$, de manera que en esta fecha el cementerio estaba en uso y obviamente el poblado se encontraba en crecimiento. De ser así podríamos esperar dataciones algo más tempranas para un comienzo de ocupación.

Al observar el perfil estratigráfico (ver Figura 7) se puede sugerir, con solo tres fechas coherentes, que: 
a) Los recintos del Conjunto 1, el más denso y conglomerado del asentamiento, fueron construidos antes de 70 DC.

b) Las primeras basuras arrojadas en el interior del recinto excavado, que configuran los estratos IV y III, representan dos momentos datados entre 70 y $500 \mathrm{DC}$, en secuencia y coherencia con el registro cultural.

c) Los estratos II y I deberían ser algo posteriores, pero la continuidad de rasgos culturales y económicos acentúa una distancia temporal restringida.

d) El poblado in toto pudo iniciarse algo antes de 480 AC en relación al fechado del cementerio Pircas 2.

Las diversas clases de sitios testeados y parcialmente datados de la zona de ocupación de Pircas se han dispuesto en un cuadro comparativo con los períodos cronometrados en Caserones, con el que comparte un espacio productivo (ver Figura $2 b$ ). Pircas resulta contemporáneo con el cementerio de cuerpos enturbantados adosados a la banda norte (Tarapacá 40A y probablemente B) y los basurales del fondo de la quebrada (Tarapacá 6 o Caserones Norte), incluyendo el Período III del poblado de Caserones. Como se plantea que el momento de construcción de Pircas 1 puede ser anterior a $480 \mathrm{AC}$ cuando el cementerio Pircas 2 era usado, se propone que su comienzo real de ocupación puede bajar hipotéticamente hasta el Período II de Caserones entre $400 \mathrm{AC}$ a 0 . De esta manera, tanto las fechas recibidas como el cálculo supuesto para el comienzo de ocupación permiten señalar una particular sincronía de episodios con el asentamiento Caserones, con el que difiere hasta ahora en términos estructurales, patrón de disposición residencial y rasgos culturales-tecnológicos diagnósticos. Estos dos episodios sincrónicos con contenidos culturales distintos en un territorio común, sin otras ocupaciones aledañas, abren una singular perspectiva de análisis.

\section{Conclusiones preliminares}

Las primeras reflexiones que surgen para ordenar la problemática vigente se pueden resumir en los siguientes términos:

a) El asentamiento Pircas se define por un típico patrón habitacional disperso asociado a cementerios, geoglifos y campos de ofrendas, datado parcialmente en una primera etapa de ocupación postconstrucción entre 70 y 500 DC. Un momento relativamente inicial se dataría en 480 AC. Sin embargo, la secuencia de episodios y la identificación de contextos representativos de los distintos tipos de sitios y estructuras requieren de un mayor esfuerzo analítico.

b) El registro cultural muestra cierta tendencia a identificar rasgos distintos a los recurrentes en esta época en otros sitios funerarios y habitacionales de tierras bajas de la Subárea Valles Occidentales. Pero el registro de especímenes como grandes cestos, capachos y cerámica alisada monocrama lo sitúan en principio en el amplio espectro de agricultores tempranos de los valles bajos. Tal situación se continúa evaluando a través de la ampliación de los tests estatigráficos.

c) Se advierte un singular énfasis en la ocupación de un amplio territorio para fines residenciales que se exterioriza por medio de un dominio del espacio circundante con expresiones ideológicas (geoglifos, ofrendas, marcas y grandes círculos en torno a los recintos). Esto parece compatible con la expresión simbólica de situaciones de identidad territorial y étnica apoyada por un planteamiento litúrgico muy complejo cuya lectura sintáctica puede establecerse a lo largo del espacio ocupado in toto. Esta evidencia que implica una combinación de la data productiva e ideológica es ideal para aplicar una estrategia de investigación que incluya ambos factores dentro de un proceso explicativo único (relación de necesidades de grandes espacios de uso litúrgico y gestación de un patrón habitacional disperso).

d) Los estudios en curso están orientados a contrapuntear la dirección del desarrollo sociocultural y productivo de Caserones con Pircas, para lo cual se muestrean otros conjuntos y sitios de la red de interacción con el objeto de rectificar las propuestas en términos de cuantificacion y cualificación del registro de campo.

e) Los componentes de Pircas al contrastarlos preliminarmente con los escasos asentamientos tempranos documentados y cronometrados en el norte de Chile (Caserones, Guatacondo y Tulor), resultan poco comparables. Tal modelo arquitectónico inédito implica situaciones de filum, imbricaciones intergrupales y procesamiento intracultural muy intenso, dentro del régimen de adaptación a tierras 
áridas en el desierto, de lo cual aún no sabemos lo suficiente.

f) De uno u otro modo, el conocimiento teórico del sedentarismo en los valles bajos muestra ahora nuevas variables que explicitarán mejor la naturaleza desigual del contenido sociocultural del temprano proceso de agriculturación. Hasta ahora ha prevalecido el criterio funerario para postular y rotular los complejos episodios agrarios iniciales. No obstante queda fuera de duda que antes de definir un modelo explicativo debidamente contrastado se requiere de una rigurosa factografía de la actividad residencial en donde el objetivo holístico es más implícito. Después de todo, cada asentamiento no es menos que el mayor artefacto manufacturado por el hombre.

Agradecimientos El autor agradece la participación de los diferentes investigadores que evalúan distintas colecciones y problemas provenientes del Proyecto Caserones: P. Advis (arquitectura), T. Bird y D. Pearsall (paleobotánica), B. Hesse (paleozoología), L. F. Ferreira (paleoparasitología), V. Standen (antropología física), J. Varela (geociencias) y M. Allison (paleopatología). A D. True y B. Meggers por su constante colaboración y a los colegas de la Facultad de Arquitectura e Instituto de Arqueología de esta casa de estudios por su inapreciable enseñanza e intercambio de experiencias.

\section{REFERENCIAS CITADAS}

GONZALEZ, A. R. y V. NUÑEZ REGUEIRO, 1962. Preliminary report on archaeological research in Tafi del Valle, NW Argentina. Actas del $34^{\circ}$ Congreso Internacional de Americanistas, pp. 485-496. Viena.

NUÑEZ, L., 1965. Prospección arqueológica en el norte de Chile. Estudios Arqueológicos 1: 9-35.

1972. Caserones, una aldea prehispánica del norte de Chile. Estudios Arqueológicos 2: 25-29.

_ 1981. Emergencia de sedentarización en el desierto chileno: Subsistencia agraria y cambio sociocultural. Creces 11 (2): $33-38$
1982. Temprana emergencia de sedentarismo en el desierto chileno: Proyecto Caserones. Chungara 9: 80-122.

NUÑEZ REGUEIRO, V., 1971. La Cultura Alamito de la Subárea Valliserrana del Noroeste Argentino. Journal de la Société des Américanistes, pp. 7-62.

TRUE, D., L. NUÑEZ y P. NUÑEZ, 1970. Archaeological investigation in Northern Chile: Project Tarapacá. American Antiquity 35 (2): 170-184. 